\title{
Aplikasi Pemantau Perangkat Jaringan Berbasis Web Menggunakan Protokol SNMP dan Notifikasi SMS
}

\author{
Shofa Taftazanie, Agung Budi Prasetijo, Eko Didik Widianto*) \\ Program Studi Sistem Komputer, Fakultas Teknik, Universitas Diponegoro \\ Jl. Prof. Soedarto, SH, Kampus Undip Tembalang, Semarang, Indonesia 50275
}

\begin{abstract}
Device monitoring tool on a computer network is required by the administrator to perform management of the device. This research produces web applications using PHP that is capable of monitoring and collecting device information on the network. This app uses SNMP and syslog protocols to perform monitoring on the device. Device information will be collected on the monitor server and displayed in web-based applications. This app using crontab to be able to monitor every minute. This application can also send a warning message in the form of SMS and email to the administrator when an error occurs on the device so that handling is expected to be faster done. This web application can make it easier for administrators to monitor devices anywhere.
\end{abstract}

Keywords - Monitoring; SNMP; syslog; SMS; PHP; crontab

\begin{abstract}
Abstrak - Pemantauan perangkat pada suatu jaringan komputer sangat diperlukan oleh administrator untuk melakukan manajemen perangkat tersebut. Penelitian ini menghasilkan aplikasi web menggunakan PHP yang mampu melakukan pemantauan dan pengumpulan informasi perangkat di jaringan. Aplikasi ini menggunakan protokol SNMP dan syslog untuk melakukan pemantauan pada perangkat. Informasi perangkat akan dikumpulkan pada server monitor dan ditampilkan pada aplikasi berbasis web. Aplikasi menggunakan crontab agar dapat melakukan pemantauan setiap menit. Aplikasi juga dapat mengirimkan pesan peringatan berupa SMS dan email kepada administrator saat terjadi kesalahan pada perangkat server sehingga penanganan diharapkan dapat lebih cepat dilakukan. Aplikasi web ini dapat mempermudah administrator dalam memantau perangkat dimana saja.
\end{abstract}

Kata Kunci - Pemantauan; SNMP; syslog; SMS; PHP; crontab

\section{Pendahuluan}

Administrator jaringan komputer bertugas untuk melakukan pemantauan terhadap suatu jaringan komputer. Kesalahan atau kerusakan pada server rentan untuk terjadi pada perangkat jaringan atau server yang mengakibatkan masalah pada akses client. Server yang bekerja terus-menerus dapat mencapai ambang batas seperti pemakaian CPU, RAM, atau penyimpanan yang

*) Penulis korespondensi (Eko Didik Widianto)

Email: didik@live.undip.ac.id tersedia. Manajemen perangkat yang efisien dan otomatis diperlukan dalam jaringan yang besar karena sangat sulit untuk mengelola perangkat hanya dengan usaha manusia [1]. Kerusakan pada aplikasi sering terjadi yang disebabkan oleh konfigurasi yang tidak sesuai dengan aplikasi. Terkadang pesan kesalahan yang ditampilkan oleh sistem mengarahkan pada file log aplikasi.

Informasi log dapat digunakan oleh administrator untuk melihat dan memantau aktivitas perangkat. Log file berisi satu atau lebih log atau aktivitas yang telah dijalankan oleh aplikasi yang setidaknya terdapat waktu ketika aktivitas dijalankan [2]. Manajemen log sangatlah dibutuhkan oleh administrator, guna untuk mempermudah melihat log pada setiap perangkat. Protokol syslog menyediakan jalur yang memungkinkan perangkat mengirimkan pesan log melaui jaringan IP ke event collector [3].

Pemantauan bukan hanya melihat aktivitas jaringan melalui log saja, namun juga dapat mengetahui kondisi perangkat. RAM, storage, dan availability perlu dilakukan pemantauan untuk menjaga perangkat dalam kondisi yang optimal. Simple Network Management Protocol (SNMP) adalah sebuah protokol yang digunakan untuk memonitor perangkat pada jaringan, seperti memonitor peralatan jaringan (seperti switch), peralatan komputer, dan perangkat lainnya [4].

Pradikta dkk. [5] memaparkan perancangan sistem pemantauan menggunakan protokol SNMP. Protokol SNMP digunakan untuk mengumpulkan data perangkat dengan melakukan permintaan informasi pada perangkat. Informasi yang dikumpulkan digunakan untuk menghitung nilai availability pada perangkat. Basis data digunakan untuk menampung hasil dari permintaan SNMP.

Syuhada [6] memaparkan perancangan sebuah prototipe perangkat yang dapat mengirim pesan laporan jika terjadi kesalahan pada perangkat. Pendeteksian kesalahan dilakukan dengan menggunakan ping pada setiap perangkat dan service. Penelitian tersebut menggunakan syslog sebagai protokol untuk mengumpulkan log perangkat. Rsyslog digunakan sebagai aplikasi untuk menyimpan log pada basis data yang telah ditentukan.

Taufan dkk. [7] memaparkan perancangan sistem pemantauan secara berkala setiap 10 menit. Sistem menggunakan script yang akan melakukan PING pada server perangkat. Script dijalankan dengan menggunakan crontab setiap 10 menit secara otomatis. 
Jika terjadi kesalahan pada server, sistem akan mengirimkan pesan peringatan pada administrator.

Peringatan kesalahan dapat membantu administrator dalam mengatasi masalah yang terjadi pada server dengan cepat. Administrator tidak dapat setiap waktu memantau seluruh aktivitas perangkat pada jaringan, sehingga diperlukan sebuah sistem peringatan untuk lebih menghemat waktu. Sistem peringatan ini dapat ditingkatkan fasilitasnya dengan pengiriman pesan peringatan melalui media SMS (Short Message Service) yang langsung terkirim ke administrator [8].

Prakdikta dkk. [5] menggunakan protokol SNMP untuk melakukan pemantauan namun tidak terdapat peringatan kondisi perangkat. Syuhada [6] menggunakan protokol syslog untuk mengumpulkan $\log$. Sistem melakukan peringatan dengan menggunakan PING pada setiap server. Namun, sistem tidak dapat mendeteksi kesalahan dalam penggunaan RAM dan storage pada server. Taufan dkk. [7] membangun sistem yang dapat memonitor server setiap 10 menit. Pendeteksian masalah menggunakan PING ke server tujuan. Awaj dkk. [8] memantau kondisi lingkungan, yaitu suhu dan kelembaban, di ruang server dan mengirimkan pesan peringatan melalui SMS. Penelitian ini menghasilkan aplikasi berbasis web yang dapat diakses oleh administrator melalui berbagai perangkat elektronik seperti smartphone, laptop, dan gadget lainnya yang mendukung untuk mengakses web. Sistem dapat melakukan pemantauan penggunaan RAM dan storage pada perangkat. Sistem dapat melakukan peringatan kesalahan melalui SMS kepada administrator. Sistem dapat mendeteksi penggunaan RAM, storage dan availability server dengan menggunakan permintaan SNMP. Protokol Syslog digunakan untuk menganalisis kesalahan yang terjadi pada perangkat.

\section{Metode DAN BAHAN}

Metode penelitian yang digunakan dalam mengembangkan sistem pemantauan jaringan komputer terdiri dari 4 tahap yaitu identifikasi masalah, desain aplikasi dan sistem, pembuatan sistem dan aplikasi, dan implementasi. Beberapa sistem pemantauan yang telah ada dikaji, seperti Cacti dan LogAnalyzer. Cacti adalah aplikasi open source network monitoring dan grafik dengan menggunakan PHP, MySQL, dan RDDTool [9]. LogAnalyzer adalah sebuah aplikasi berbasis web yang digunakan untuk menampilkan data log pada Rsyslog [10].

Kebutuhan fungsional dari aplikasi pemantau yang dikembangkan adalah sistem dapat mengumpulkan log aktivitas dari perangkat remote dengan menggunakan syslog. Server pemantauan dapat mengambil dan mengumpulkan informasi komputer agent menggunakan protokol SNMP dalam interval setiap satu menit. Server pemantauan dapat mengirimkan pesan peringatan melalui SMS dan email. Kebutuhan fungsional yang terakhir yaitu sistem
Tabel 1. Spesifikasi Komputer

\begin{tabular}{cc}
\hline Komponen & Server \\
\hline Prosesor & Intel Pentium CPU G620 2.60 GHz \\
Motherboard & ECS H61H2-M12 \\
RAM & $2 \mathrm{~GB}$ \\
HDD & $320 \mathrm{~GB}$ \\
NIC & 1 Fast Ethernet \\
\hline
\end{tabular}

aplikasi dapat menampilkan log dan informasi perangkat yang telah dikumpulkan oleh sistem.

Perangkat keras digunakan sebagai wadah sistem dan penunjang agar sistem berjalan, yaitu berupa dua unit komputer dengan pembagian 1 sebagai server pemantauan dan 1 sebagai server untuk dilakukan pemantauan. Perangkat komputer memiliki spesifikasi pada Tabel 1. Unit Mikrotik Routerboard digunakan sebagai perangkat jaringan untuk pemantauan dan sebagai switch yang menghubungkan antar perangkat. Sebuah modem untuk mengirimkan pesan peringatan berupa SMS. Laptop Asus A43SJ difungsikan untuk melakukan konfigurasi sistem, membuat aplikasi dan sebagai klien. Media fisik komunikasi antar perangkat menggunakan kabel UTP.

Perangkat server pemantauan dan server yang dipantau menggunakan sistem operasi Debian 8 (wheezy). Aplikasi untuk mendukung fungsi menyentralisasi log setiap perangkat ke server pemantauan dan disimpan pada basis data menggunakan Rsyslog. Net SNMP digunakan untuk untuk mengambil informasi dari setiap perangkat.

Pembuatan aplikasi pemantauan menggunakan bahasa pemrograman PHP. Pengembangan aplikasi menggunakan framework CodeIgniter. Apache2 digunakan sebagai server web untuk menampung aplikasi agar dapat diakses. Basis data pada server pemantauan menggunakan MySQL. MySQL tersedia sebagai perangkat lunak gratis di bawah lisensi GNU GPL (General Public License).

Sistem pemantauan terdapat fungsi peringatan dengan mengirimkan pesan SMS dan email. Pesan SMS dikirimkan dengan menggunakan aplikasi SMS gateway GAMMU. Sedangkan pengiriman email menggunakan mail server SSMTP melalui Gmail. Konfigurasi pada server dilakukan secara remote dengan menggunakan aplikasi Putty. Putty adalah perangkat lunak remote console/terminal yang digunakan untuk melakukan remote access ke komputer dan perangkat jaringan dengan menggunakan $\mathrm{SSH}$, Telnet, atau serial. Melakukan percobaan pada aplikasi menggunakan Mozilla Firefox sebagai penjelajah web.

Desain topologi sistem pemantauan ini terdiri dari berbagai entitas yang terlibat dalam pembangunan sistem. Entitas-entitas tersebut dihubungkan menggunakan suatu topologi star. Topologi star mempunyai kontrol terpusat, semua link harus melewati pusat yang menyalurkan data tersebut kesemua simpul atau client yang dipilihnya [11]. Topologi ini memungkinkan server pemantauan (manager) untuk menerima dari agent dan client (agent) untuk mengirimkan informasi perangkat ke manager seperti 


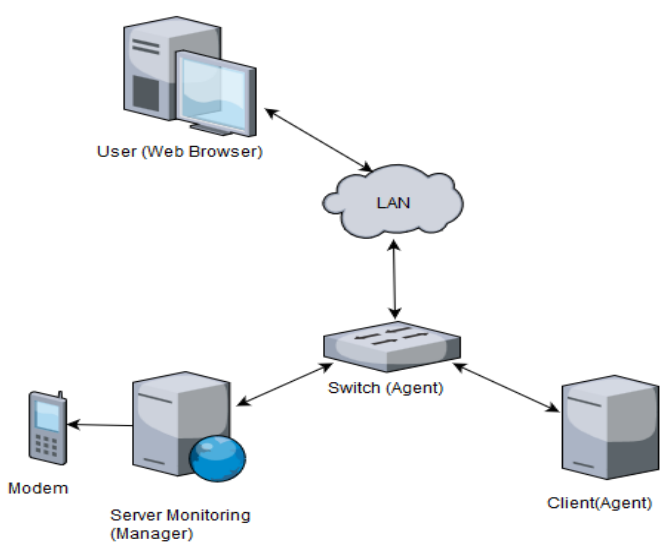

Gambar 1. Desain topologi fisik

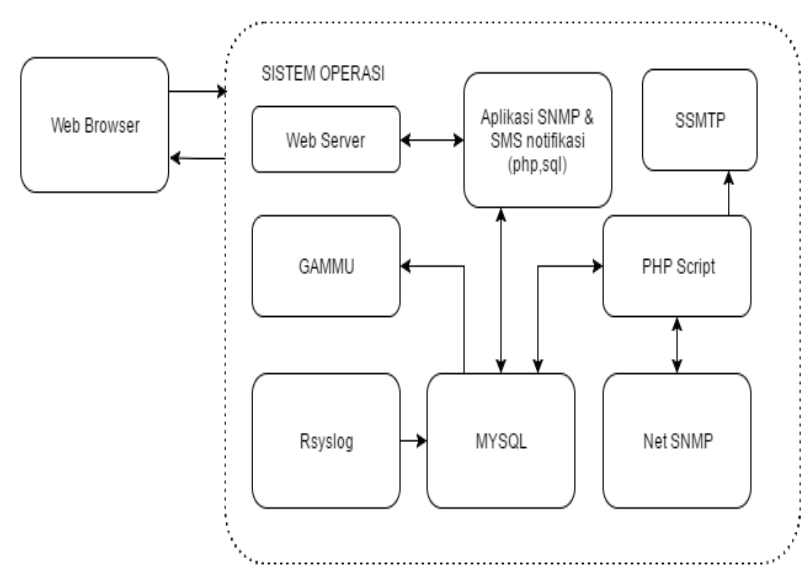

Gambar 2. Desain perangkat lunak sistem

pada Gambar 1. Setiap perangkat memiliki fungsi masing-masing sebagai manager, agent, atau client yang menggunakan aplikasi sistem pemantauan.

Gambar 2 menunjukkan desain sistem perangkat lunak pada server dapat berkomunikasi sehingga membentuk sebuah sistem. Perangkat lunak terdiri atas komponen software yang digunakan dalam sistem pemantauan. Perancangan dilakukan pada dua tahap yaitu penggunaan protokol SNMP dan Syslog sebagai pengumpul informasi. Sistem dirancang untuk menjalankan proses permintaan SNMP dan pendeteksian kesalahan pada perangkat. Pengumpulan log pada aplikasi sistem pemantauan ini menggunakan syslog. Rsyslog (Rocket-fast System for log Processing) adalah sebuah sistem logger yang menggunakan protokol syslog berfungsi mengumpulkan log pada basis data yang ada [12]. Pendeteksian pada ketersediaan service menggunakan port aplikasi. Port merupakan bagian dari pengalamatan yang telah ditentukan yang berfungsi sebagai jalur dari aplikasi ke transport layer atau dari transport layer ke aplikasi [13]. Data ini kemudian disimpan ke database Mysql.

Proses kerja sistem pemantauan ditunjukkan pada Gambar 3. Diagram alir tersebut menjelaskan ng proses pengumpulan informasi perangkat menggunakan SNMP. Informasi yang dikumpulkan disimpan ke dalam basis data dan informasi digunakan untuk mendeteksi kesalahan. Diagram tersebut menjelaskan pemprosesan data yang dikumpulkan untuk dijadikan sebagai informasi perangkat dalam kondisi baik atau tidak sesuai dengan parameter yang telah ditentukan. Peringatan berupa SMS akan dikirim jika perangkat dalam kondisi tidak baik.

Perancangan basis data membahas tentang basis data yang digunakan oleh sistem aplikasi ini. Beberapa tabel basis data yang digunakan default dari aplikasi pihak kedua seperti Gammu dan syslog. Basis data akan menyimpan hasil dari pengumpulan data menggunakan protokol SNMP. Basis data digunakan untuk mempermudah dalam melakukan pengolahan serta penyimpanan data dalam jumlah banyak. Entity Relationship Diagram (ERD) dari aplikasi pemantauan ditunjukkan pada Gambar 4.

\section{Hasil dan Pembahasan}

Pengujian sistem dilakukan untuk memeriksa kinerja antar komponen sistem yang diimplementasikan. Tujuan pengujian sistem adalah untuk memastikan bahwa elemen-elemen atau komponen-komponen dari sistem telah berfungsi sesuai dengan yang diharapkan. Pengujian tersebut meliputi pengujian syslog, sistem pemantauan SNMP, sistem peringatan perangkat, pengujian service, dan pengujian aplikasi secara keseluruhan.

Kebutuhan fungsional pada sistem pemantauan adalah server dapat mengumpulkan log aktivitas dari perangkat agent dengan menggunakan syslog. Pengumpulan log yang dimaksud adalah menampung log dari perangkat agent yang terdapat syslog kedalam basis data yang telah dibuat secara realtime. Sistem yang diinginkan adalah ketika perangkat agent menghasilkan $\log$, kemudian $\log$ dikirim ke server pemantauan dan sistem menyimpan pada basis data. Berdasarkan Gambar 5, setelah dilakukan aktifitas pada tiap perangkat agent terdapat data baru pada basis data tabel SystemEvents. Data tersebut adalah $\log$ aktifitas yang dihasilkan oleh perangkat agent dan dikirimkan ke manajer server untuk disimpan dalam basis data. Hasil pengujian syslog menunjukkan sistem dapat mengumpulkan log tiap perangkat dan disimpan pada basis data.

Berdasarkan kebutuhan fungsional pada sistem pemantauan adalah server pemantau dapat mengambil dan mengumpulkan informasi komputer agent menggunakan protokol SNMP dalam waktu interval satu menit. Pengumpulan informasi komputer menggunakan protokol SNMP yang dijalankan pada file PHP. Program PHP bertugas untuk menyimpan data hasil dari permintaan SNMP ke dalam basis data. Sistem yang diinginkan adalah dapat melakukan penambahan data pada basis data tiap menit. Gambar 6 menunjukkan hasil pengujian bahwa sistem dapat melakukan permintaan SNMP pada perangkat agent. Request dilakukan oleh sistem pada setiap perangkat dalam interval waktu satu menit. Informasi yang dikumpulkan disimpan pada basis data tabel $t b \_$monitor. 


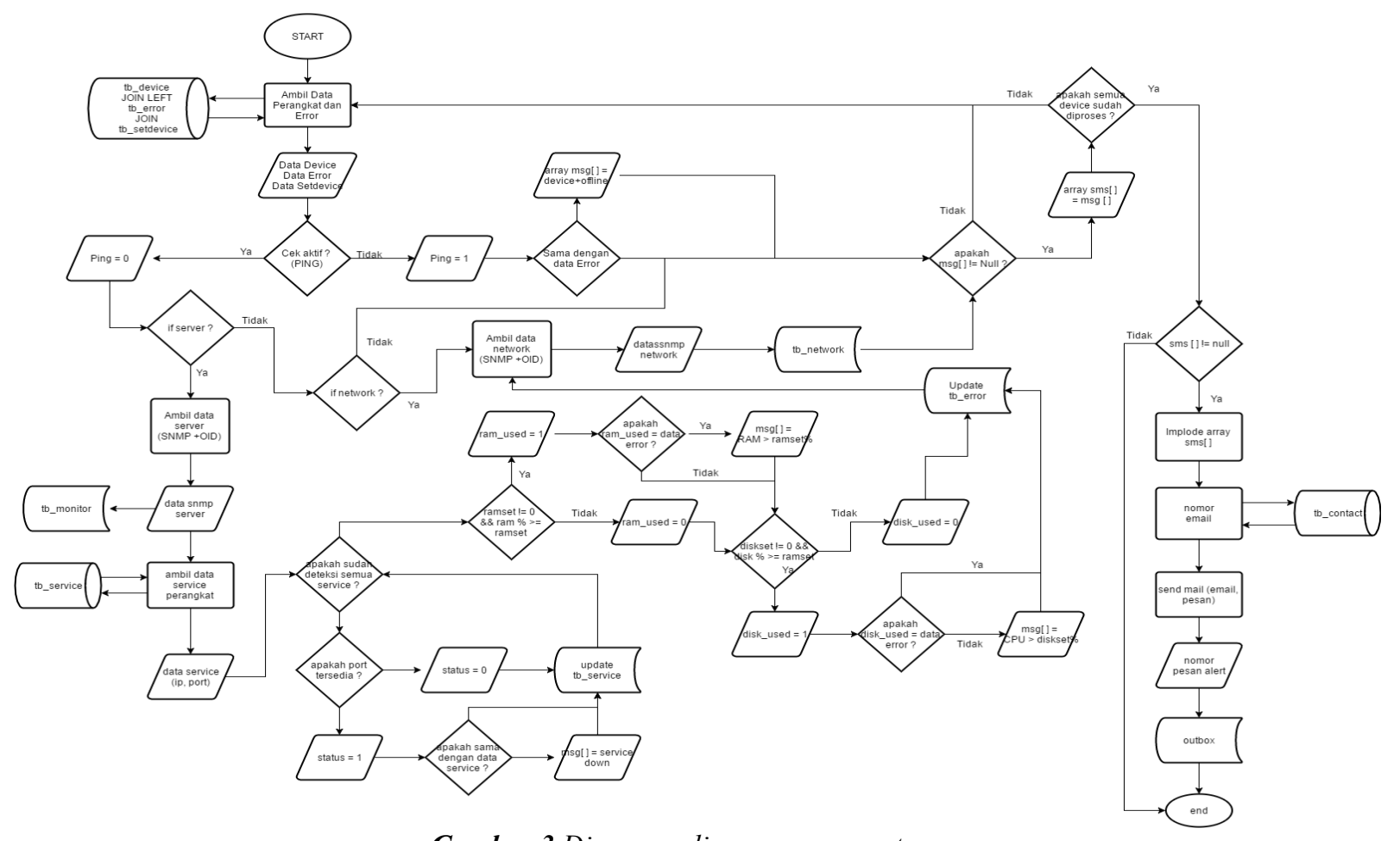

Gambar 3.Diagram alir proses pemantauan

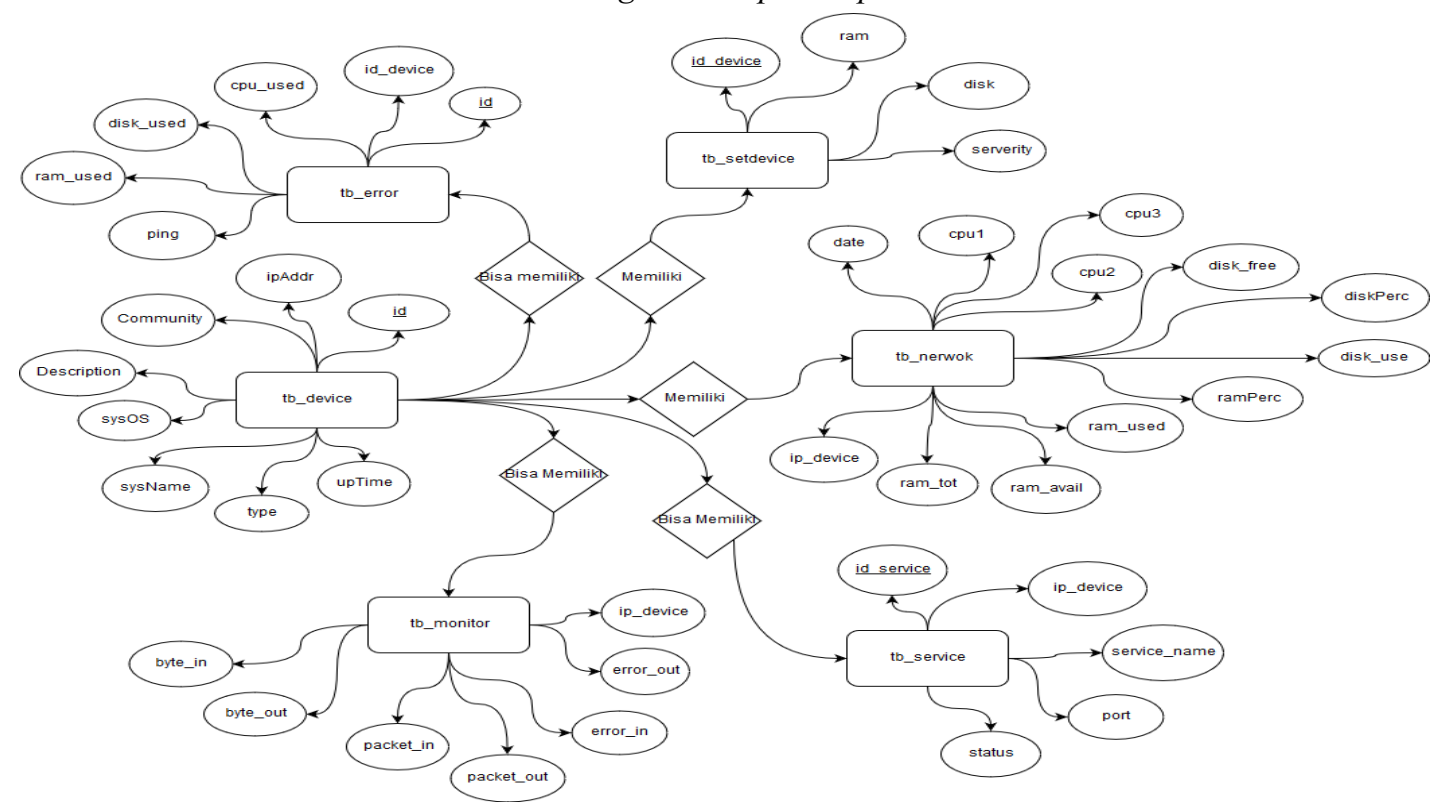

Gambar 4. ERD basis data pemantauan

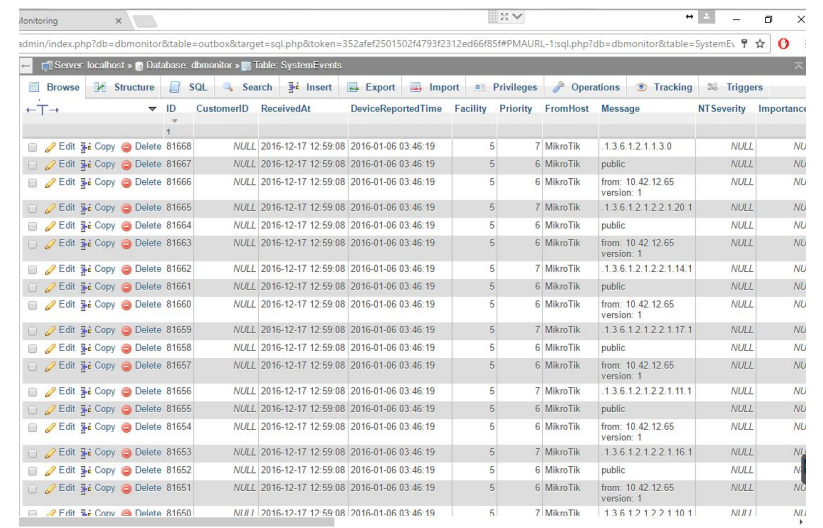

Gambar 5. Tabel SystemEvents

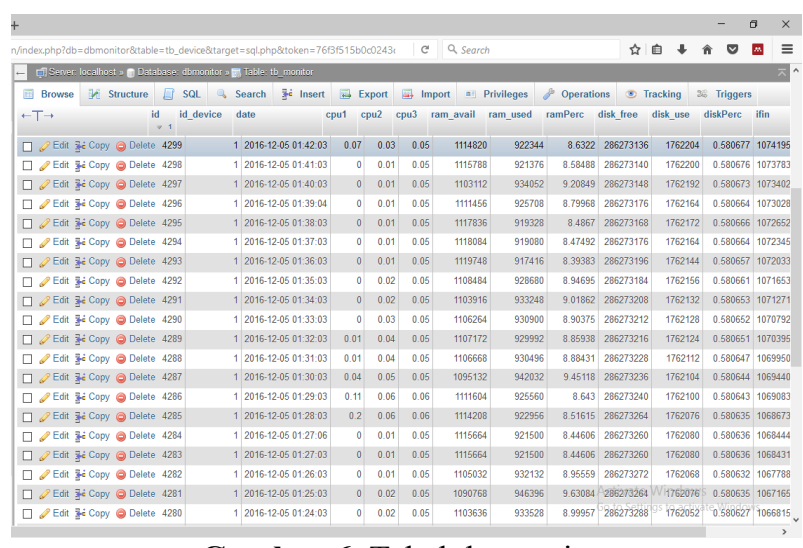

Gambar 6. Tabel tb_monitor 


\begin{tabular}{|c|c|c|c|c|}
\hline$\leftarrow T \rightarrow$ & id_device & ram_used & disk_used & ping \\
\hline$\square$ Edit 굴 Copy $\odot$ Delete & 1 & 0 & 0 & 0 \\
\hline$\square$ Edit żं Copy $\odot$ Delete & 2 & 0 & 0 & 0 \\
\hline$\square$ Edit 감: Copy $\odot$ Delete & 3 & 0 & 0 & 0 \\
\hline
\end{tabular}

Gambar 7. Kondisi awal status perangkat

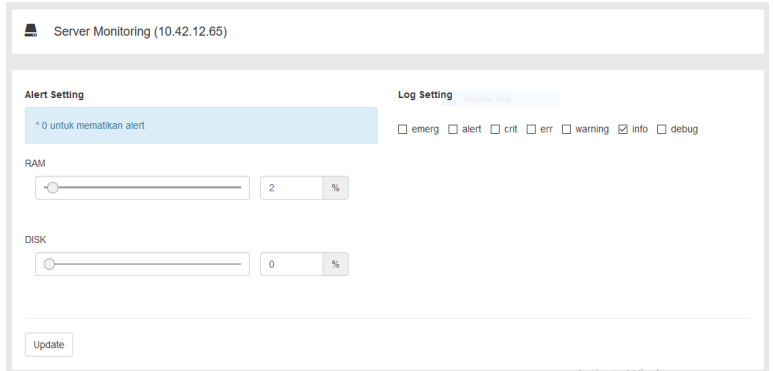

Gambar 8. Pengaturan pada perangkat Monitoring Server

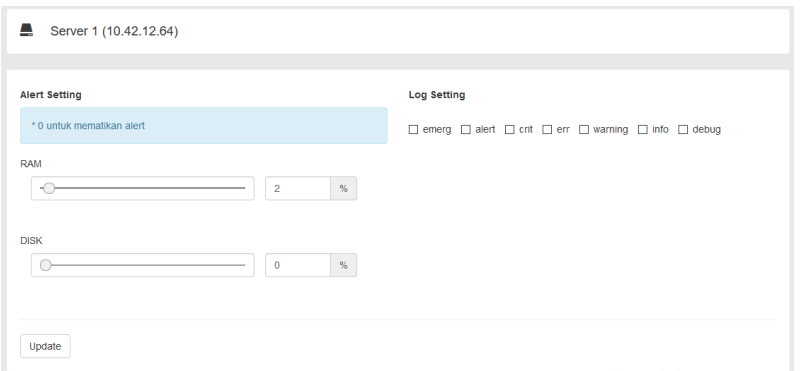

Gambar 9. Pengaturan pada perangkat Server 1

\begin{tabular}{|c|c|c|c|c|}
\hline$\leftarrow T \rightarrow$ & id_device & ram_used & disk_used & ping \\
\hline$\square$ Edit 굴: Copy $\odot$ Delete & 1 & 1 & 0 & 0 \\
\hline 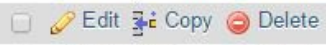 & 2 & 1 & 0 & 0 \\
\hline 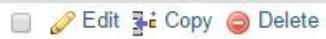 & 3 & 0 & 0 & 0 \\
\hline
\end{tabular}

Gambar 10. Kondisi status RAM perangkat melebihi batas

Berdasarkan kebutuhan fungsional pada sistem pemantauan adalah aplikasi dapat mengirimkan pesan peringatan melalui SMS dan email. Pesan peringatan berupa informasi perangkat dalam keadaan melebihi batas yang telah ditentukan. Sistem hanya akan mengirimkan pesan sekali jika tidak ada perubahan terjadi. Gambar 8 menunjukkan kondisi awal ketika perangkat dalam keadaan normal. Selanjutnya dilakukan pengaturan penggunaan RAM pada aplikasi pemantauan sistem. Setiap perangkat dilakukan pengaturan batas penggunaan RAM 2\% dari jangkauan 1\% sampai 100\% seperti pada Gambar 8 dan Gambar 9. Sistem akan memberi peringatan jika penggunaan RAM sampai $2 \%$ atau lebih dari total kapasitas RAM.

Untuk setiap perubahan status, aplikasi hanya mengirimkan 1 buah SMS saja. Gambar 10 menunjukkan bahwa nilai berubah menjadi "1" karena terjadi kesalahan pada perangkat. Perubahan nilai akan membuat sistem untuk mendeteksi, jika perubahan dari nilai " 0 " menjadi " 1 " berarti terjadi kesalahan sistem dan sistem mengirimkan pesan peringatan, sedangakan jika nilai berubah dari "1" menjadi "0" maka sistem tidak akan melakukan pengiriman pesan.
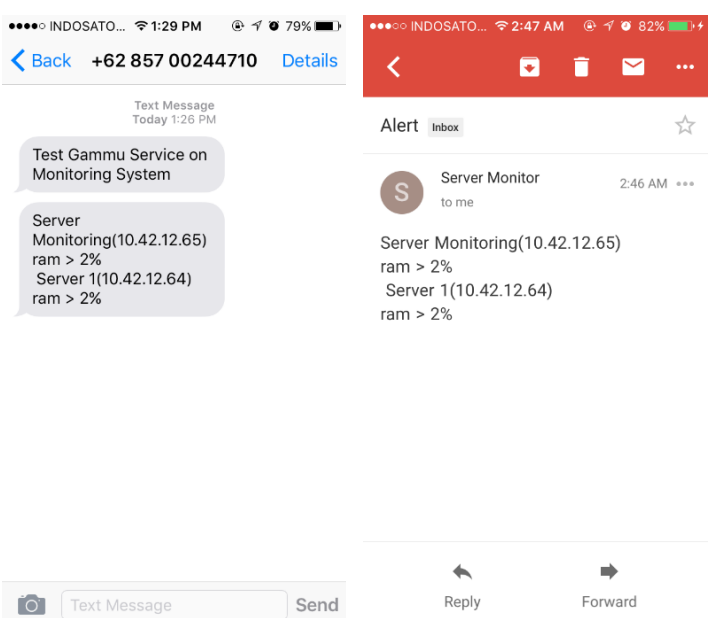

Gambar 11. Pesan peringatan SMS dan email

Tabel 2. Hasil pengujian pesan peringatan

\begin{tabular}{cccc}
\hline Perangkat & RAM & DISK & PING \\
\hline $\begin{array}{c}\text { Monitoring } \\
\text { Server }\end{array}$ & Berhasil & Berhasil & Berhasil \\
Server 1 & Berhasil & Berhasil & Berhasil \\
\hline
\end{tabular}

\begin{tabular}{|c|c|c|c|c|}
\hline \multicolumn{2}{|c|}{ service name } & \multicolumn{2}{|l|}{ port } & Add service \\
\hline & Service & & Port & Status \\
\hline $\mathbf{x}$ & web server server1 & & 80 & open \\
\hline $\boldsymbol{x}$ & telnet server1 & & 23 & open \\
\hline$x$ & ssh server 1 & & 22 & open \\
\hline $\mathbf{x}$ & pop3 server1 & & 110 & open \\
\hline $\mathbf{x}$ & imap2 server1 & & 143 & open \\
\hline
\end{tabular}

Gambar 12. Pemambahan service pada basis data Hasil pengujian pada setiap perangkat menunjukkan sistem dapat mengirimkan pesan peringatan ke nomor dan email yang terdaftar. Ketika perangkat terjadi kesalahan status akan berubah menjadi nilai 1, namun ketika perangkat dalam kondisi normal status akan bernilai 0 . Pesan peringatan dikirim hanya sekali selama belum terjadi perubahan nilai status pada perangkat.

Berdasarkan kebutuhan fungsional pada sistem pemantauan adalah dapat mengirimkan pesan peringantan melalui SMS dan email. Pesan peringatan berupa informasi availability service yang berjalan pada perangkat. Service yang dimaksud adalah aplikasi seperti web server, mail server, basis data, dan aplikasi lainnya. Service yang akan dilakukan pemantauan sesuai dengan yang terdaftar pada basis data. Berdasarkan Gambar 11 setelah diberikan kondisi pada tiap perangkat pesan peringatan terkirim melalui sms dan email. Pesan dikirimkan hanya sekali selama tidak terjadi perubahan pada kondisi sebelumnya. Tabel 2 menunjukan hasil pengujian terhadap pemakaian RAM, disk, dan ketersediaan perangkat (offline/online).Pengujian dilakukan dengan 


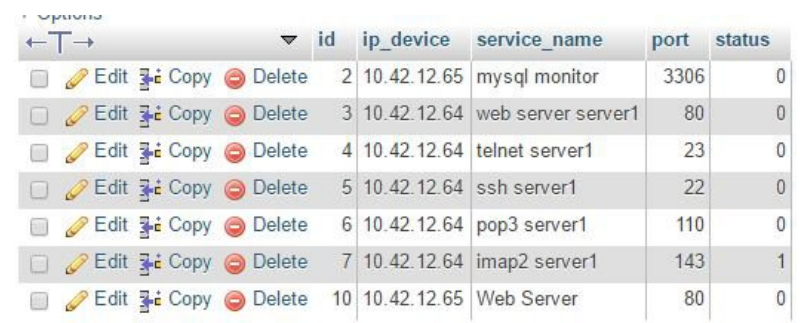

Gambar 13. Perubahan basis data tb_service pada service imap2

\begin{tabular}{|c|c|c|c|c|}
\hline \multicolumn{2}{|c|}{ service name } & \multicolumn{2}{|l|}{ port } & Add service \\
\hline & \multicolumn{2}{|c|}{ Service } & Port & Status \\
\hline $\mathbf{x}$ & \multicolumn{2}{|c|}{ web server server 1} & 80 & open \\
\hline $\mathbf{x}$ & \multicolumn{2}{|c|}{ telnet server 1} & 23 & open \\
\hline $\mathbf{x}$ & \multicolumn{2}{|c|}{ ssh server1 } & 22 & open \\
\hline $\mathbf{x}$ & \multicolumn{2}{|c|}{ pop3 server1 } & 110 & open \\
\hline $\mathbf{x}$ & \multicolumn{2}{|c|}{ imap2 server1 } & 143 & close \\
\hline
\end{tabular}

Gambar 14. Perubahan status pada aplikasi menjadi close

Tabel 3. Hasil Pengujian Service

\begin{tabular}{lcl}
\hline Service & Server Monitoring & Server 1 \\
\hline Web Server & Berhasil & Berhasil \\
SSH & Berhasil & Berhasil \\
Telnet & - & Berhasil \\
MySQL & Berhasil & Berhasil \\
IMAP2 & - & Berhasil \\
\hline
\end{tabular}

menambahkan service yang terdapat pada perangkat "server 1" ke dalam basis data. Penambahan service meliputi nama dan port yang digunakan oleh service. Port digunakan untuk mendeteksi service dalam kondisi tersedia atau tidak. Penambahan service dilakukan seperti pada Gambar 12.

Setelah service ditambahkan, dilakukan penonaktifan service perangkat "server 1" yang sudah terdaftar. Dalam pengujian ini, service yang dilakukan pengujian adalah service IMAP2 yang digunakan sebagai server mail pada perangkat "server 1". Penonaktifan dilakukan pada "server 1".

Setelah service nonaktif, maka sistem pemantauan akan medeteksi port yang digunakan oleh IMAP2 tidak tersedia. Sistem akan mengubah nilai status pada basis data menjadi "1" seperti pada Gambar 13. Aplikasi akan menampilkan status "close" pada tabel service seperti pada Gambar 14. Selain perubahan status pada aplikasi, juga terdapat pesan peringatan melalui SMS dan email.

Berdasarkan hasil pengujian sistem peringatan service, sistem mendeteksi melalui kesalahan pada port yang digunakan service. Ketika port tidak tersedia atau tidak dapat diakses oleh sistem, maka sistem akan mengubah nilai menjadi "1" pada basis data. Tabel 3 menunjukan hasil pengujian sistem terhadap beberapa service aplikasi pada perangkat.

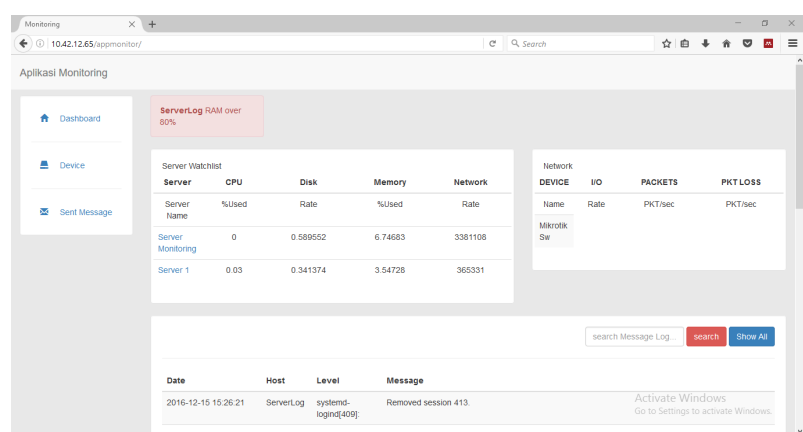

Gambar 15. Tampilan Dashboard

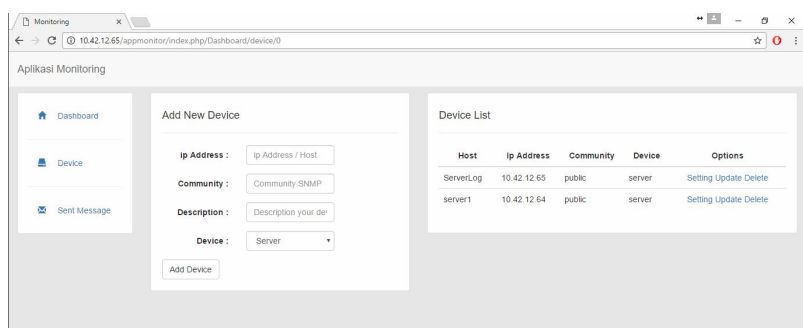

Gambar 16. Tampilan manajemen perangkat

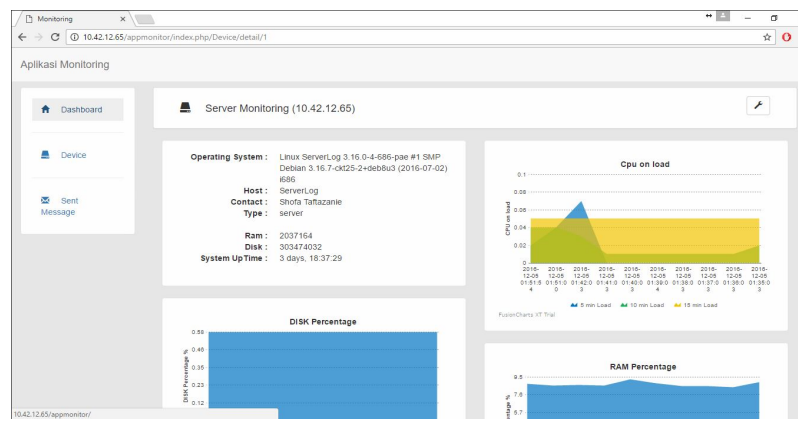

Gambar 17. Tampilan detail perangkat

Tampilan awal pada aplikasi menampilkan "dashboard" yang menyediakan informasi dan aktifitas $\log$ setiap perangkat. Aplikasi mempunyai beberapa menu, di antaranya dashboard, device, dan send message seperti pada Gambar 15. Menu "device" mempunyai submenu berisi manajemen perangkat dan daftar perangkat yang telah disimpan. Menu manajemen perangkat terdapat form untuk menambah dan mengubah informasi perangkat. Pada sebelah kanan terdapat tabel yang berisi data perangkat yang terdaftar pada aplikasi. Gambar 16 menunjukkan tampilan manajemen perangkat pada aplikasi.

Fitur detail menampilkan informasi rinci tentang perangkat yang dipilih. Informasi yang ditampilkan adalah OS perangkat, hostname, kapasitas RAM, kapasitas disk, total uptime perangkat, grafik CPU on load, grafik RAM, grafik disk, dan log perangkat seperti pada Gambar 17.

Menu pengaturan alert dan $\log$ terdapat pada detail device dan manajemen perangkat. Menu pengaturan alert dan log terdapat pengaturan RAM dan disk berupa jangkauan antara 0 sampai 100 dalam satuan persen. Jika nilainya 0 maka sistem peringatan akan menjadi tidak aktif. Pengaturan log digunakan untuk menseleksi log yang ditampilkan pada menu detail device. Gambar 18 menunjukkan tampilan pengaturan alert dan log perangkat. 


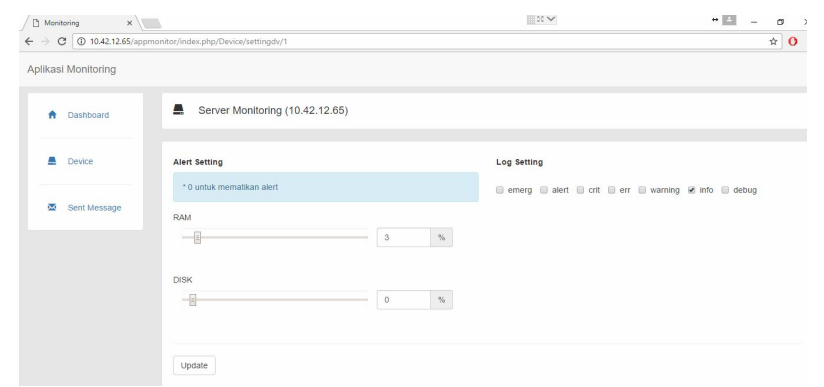

Gambar 18. Tampilan pengaturan alert dan log perangkat

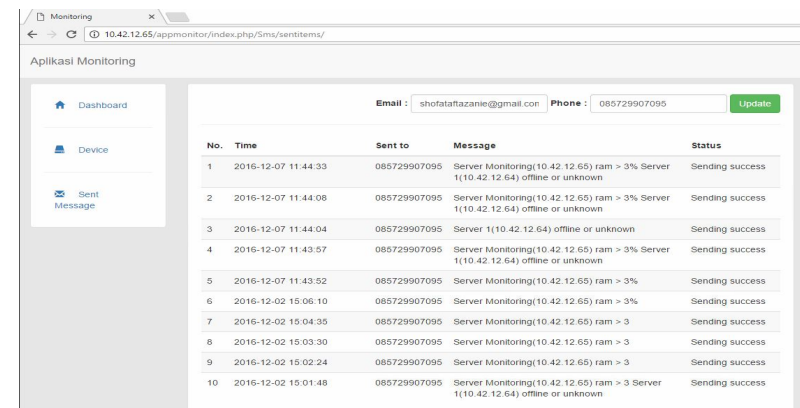

Gambar 19. Tampilan pesan alert sistem

Menu send message menampilkan riwayat pesan peringatan yang dikirimkan oleh sistem. Pada menu send message terdapat form email dan nomor yang dapat digunakan untuk mengubah email dan monor tujuan pesan peringatan dikirimkan. Gambar 19 menunjukkan tampilan menu send message pada aplikasi sistem pemantauan.

Aplikasi pemonitor server telah dapat mengumpulkan informasi perangkat-perangkat yang tersambung ke jaringan dan menganalisis kesalahan sistem yang terjadi di perangkat tersebut serta mampu menampilkan hasilnya di web. Proses pengumpulan log dilakukan dengan menggunakan protokol SNMP [5] dan memonitor sistem menggunakan syslog di perangkat tersebut [2],[3],[6]. Deteksi kesalahan atau peringatan dalam penggunaan RAM dan storage di perangkat dapat dilakukan oleh aplikasi, yang berbeda dengan [6]. Proses pemantauan dan deteksi dilakukan secara periodik menggunakan crontab [7]. Sistem dapat melakukan peringatan kesalahan melalui SMS kepada administrator [8].

\section{KESIMPULAN}

Aplikasi pemonitor server berhasil dapat mengumpulkan informasi perangkat-perangkat yang tersambung jaringan. Proses pengumpulan log dari berbagai perangkat pada jaringan berhasil dilakukan dengan menggunakan rsyslog dan dapat disimpan pada basis data. Kode PHP dapat melakukan permintaan informasi perangkat dengan menggunakan protokol SNMP pada jaringan. Data yang diambil menggunakan PHP dan protokol SNMP dapat dikumpulkan dalam basis data. Aplikasi web mampu mengelola perangkat serta menampilkan log, informasi perangkat, grafik penggunaan RAM, disk, dan CPU.

Saran untuk penelitian lanjutan dapat dilakukan pengembangan aplikasi dengan penambahan OID secara dinamis. Penelitian lanjutan dapat melakukan pengumpulan data menggunakan protokol SNMP pada berbagai jenis perangkat seperti CISCO, Windows, Mac, dan perangkat lainnya.

\section{DAFTAR PUSTAKA}

[1] K. S. Shin, J. H. Jung, J. Y. Cheon, and S. B. Choi, "Real-time network monitoring scheme based on SNMP for dynamic information," J. Netw. Comput. Appl., vol. 30, no. 1, pp. 331-353, 2007.

[2] S. O. Fageeri and R. Ahmad, "An Efficient Log File Analysis Algorithm Using Binary-based Data Structure," Procedia - Soc. Behav. Sci., vol. 129, pp. 518-526, 2014.

[3] C. Lonvick, "RFC 3164: The BSD syslog protocol," Cisco Syst. August, pp. 1-39, 2001.

[4] B. Douglas Mauro and K. Schmidt Publisher, Essential SNMP, 2nd Edition. United States of America: O’Reilly Media, Inc, 2005.

[5] R. Pradikta, A. Affandi, and E. Setijadi, "Rancang Bangun Aplikasi Monitoring Jaringan dengan Menggunakan Simple Network Management Protocol," J. Tek. ITS, vol. 2, no. 1, pp. A154-A159, 2013.

[6] A. A. Syuhada, "Prototipe SMS Report Portabel menggunakan Raspberry Pi," Teknol. Inf., pp. 1-5, 2014.

[7] H. A. W. Taufan, D. Prayogo, K. Kushartantya, "Sistem Monitoring Jaringan Pada Server Linux Dengan Menggunakan Sms Gateway," JMASIF, vol. 2, no. 3, pp. 63-72, 2011.

[8] M. F. Awaj, A. F. Rochim, and E. D. Widianto, "Sistem Pengukur Suhu dan Kelembaban Ruang Server”, J. Teknol. dan Sist. Komput., vol. 2, no. 1, pp. 40-47, 2014 doi: http://dx.doi.org/10.14710/jtsiskom.2.1.2014.40-47.

[9] D. Kundu and S. M. I. Lavlu, Cacti 0.8 Network Monitoring. Birmingham: Packt Publishing, 2009.

[10] "LogAnalyzer Basics," 2011. [Online]. Available: http://loganalyzer.adiscon.com/doc/basics.html. [Accessed: 25-Nov-2016].

[11] A. Supriyadi and D. Gartina, "Memilih Topologi Jaringan Dan Hardware Dalam Desain Sebuah Jaringan Komputer," Informatika, vol. 16, no. 2, pp. 1037-1053, 2007.

[12]R. Gerhards, "rsyslog: going up from $40 \mathrm{~K}$ messages per second to 250K," Linux Kongress, 2010.

[13] N. Wells, Sams Teach Yourself TCP/IP in 24 hours. United States of America: Pearson Education, Inc, 2009. 